\title{
EL FRACASO DE UN SISTEMA. ANÁLISIS EMPÍRICO Y DOGMÁTICO DEL CONTROL DE CLÁUSULAS ABUSIVAS EN CONTRATOS POR ADHESIÓN*
}

\author{
Carlos Pizarro Wilson**
}

\begin{abstract}
RESUMEN
El principal problema de los contratos por adhesión consiste en la presencia de cláusulas abusivas. En Chile existe un sistema de control previsto en la Ley de Protección a los Consumidores, cuya aplicación práctica se analiza en este trabajo. Se concluye que el sistema es ineficaz para proteger a los consumidores, siendo marginal su presencia en los tribunales competentes, a lo cual se suma un cúmulo de fallos disperso. Para propender a una mejora en el objetivo de proteger a los consumidores se propone un control preventivo mediante una comisión de cláusulas abusivas que convoque a los distintos actores involucrados.
\end{abstract}

CONTRATOS POR ADHESIÓN - CLÁUSULAS ABUSIVAS - CONSUMIDOR

The failure of a system. Empiric and dogmatic analysis of control over unfair terms in contracts of adhesion

\section{Abstract}

The existence of unfair terms is the major problem of contracts of adhesion. A preventive control system is in place in the Chilean Consumer Protection Law, and its practical application is the subject of analysis in this work. As a conclusion, the system is rendered as inefficient in protecting consumers, its presence being minimal in the relevant courts; in addition to this, there are several disperse rulings on the matter. In order to obtain the goal of protecting consumers, this work propounds a preventive control system by means of a commission of unfair terms of contract that would summon all the interested parties.

CONTRACTS OF ADHESION - UNFAIR TERMS - CONSUMER

* Este artículo forma parte del Proyecto Fondecyt Regular No 1050881 sobre "La eficacia del control de cláusulas abusivas en contratos por adhesión en el ordenamiento jurídico chileno".

** Abogado, Doctor en Derecho, Profesor Investigador Facultad de Derecho de la Universidad Diego Portales, República 105, Santiago de Chile, carlos.pizarro@udp. cl. Artículo recibido el 21 de febrero de 2007 y aceptado para su publicación por el Comité Editorial el 22 de octubre de 2007. 


\section{INTRODUCCIÓN}

$\mathrm{U}$ no de los problemas, si no el más relevante, en el tráfico contractual contemporáneo es la existencia de cláusulas abusivas en los contratos por adhesión. ${ }^{1}$ Para remediar la situación de desequilibrio en que se encuentra el adherente a quien se le impone el contenido contractual, los ordenamientos jurídicos han ideado diversos mecanismos. Uno de los más importantes ha sido dotar a los consumidores de una acción judicial para demandar la nulidad parcial del contrato excluyendo de las condiciones aquella cláusula que se estima abusiva. En este sentido se orienta la Ley 19.946 de Protección a los Consumidores, cuya última reforma amplió los medios de protección al introducir la cláusula general de buena fe. ${ }^{2}$ Ya estaba con antelación desde la entrada en vigencia de la citada ley una lista de cláusulas estimadas abusivas per se, denominada en la jerga jurídica "lista negra", inspirada en la legislación europea, la cual, a su turno, tuvo su fuente en la ley alemana de condiciones generales. ${ }^{3}$ De esta manera, el sistema legal de protección de los consumidores en el ámbito de los contratos por adhesión es muy similar al europeo, integrado por una cláusula general de buena fe que permite al juez moderar el contenido contractual, a través del necesario respeto del equilibro contractual, lo cual se suma a la ya señalada lista de cláusulas consideradas abusivas. El análisis de este modelo de control, denominado "represivo", por recurrirse a su implementación una vez que se ha desatado el conflicto entre las partes, tiene un interés significativo para verificar su eficacia en la protección de los consumidores.

Descrito el problema en los contratos por adhesión, así como el modelo de control dispuesto en la legislación de protección del consumidor, en este artículo nos proponemos dilucidar cuál ha sido el funcionamiento práctico de las técnicas de control a favor del consumidor a partir de un análisis empírico del mismo.

${ }^{1}$ Aunque en Chile el tema ha sido tratado por la doctrina, ésta ha tenido escasa influencia en la jurisprudencia. En Chile, la literatura atingente se divide entre textos generales y artículos específicos. Aimone Gibson, E., Derecho de protección al consumidor, Santiago, Conosur, 1998; Corral Talciani, H. (editor), Derecho del consumo y protección al consumidor, Cuadernos de Extensión, Universidad de los Andes, Facultad de Derecho, Santiago, 1999; López Santa-María, J., "Cláusulas Contractuales Abusivas y Derecho del Consumidor", en Instituciones Modernas de Derecho Civil. Homenaje al Profesor Fernando Fueyo Laneri, Santiago, Conosur, 1996; "Condiciones Generales de la Contratación y Cláusulas Abusivas”, en Cuadernos Jurídicos. Facultad de Derecho. Universidad Adolfo Ibáñez, 1996, N 4; Pizarro Wilson, C., "La eficacia del control de las cláusulas abusivas en el derecho chileno”, en Revista Estudios Socio-Jurídicos, Universidad del Rosario, Bogotá, Colombia, 2004; La protección de los consumidores en materia contractual, Santiago, Conosur, 1999; Tapia Rodríguez, M. y Valdivia Olivares, J. M., Contrato por adhesión: Ley 19.496, Santiago, Jurídica, Santiago, 2002; Veloso Valenzuela, P., "Cláusulas abusivas" en Instituciones modernas de derecho civil: homenaje al profesor Fernando Fueyo Laneri, Santiago, Conosur, 1996.

${ }^{2}$ De la Maza Gazmuri, I., "El control de las cláusulas abusivas y la letra g)”, en RChDP, No 3, 2004 , pp. 35 y ss.

${ }^{3}$ Pizarro Wilson. La eficacia del control..., op. cit. 
En primer lugar se realizará una descripción del ámbito de la investigación y la metodología empleada, señalando las estadísticas más relevantes a fin de constatar el impacto y la eficacia del sistema de control (I), para, en segundo lugar, analizar desde un punto de vista dogmático las sentencias recopiladas en la investigación (II).

\section{El ESTUDIO EMPÍRICO. METOdOLOGÍA Y ESTAdÍSTICAS}

La investigación se planteó como objetivo verificar la aplicación del modelo de control previsto en la Ley de Protección al Consumidor y, más precisamente, cómo los jueces de Policía Local utilizaban el artículo 16 de la referida ley. ${ }^{4}$ Para esto se consideraron las causas tramitadas por juzgados de Policía Local de la Región Metropolitana. Se escogió la Región Metropolitana por su relevancia en el número de habitantes que concentra y su actividad comercial, así como la factibilidad para realizar la investigación en terreno. ${ }^{5}$

En la Región Metropolitana existen 68 Juzgados de Policía Local, siendo considerados para el estudio 43, que representan un $63 \%$ del total. Se escogieron éstos teniendo en cuenta criterios de relevancia de causas de protección al consumidor, acceso y disposición de la información. La aplicación de estos parámetros significó excluir de la muestra un total de 17 juzgados localizados en comunas rurales o semirurales presumiendo una escasa relevancia en la aplicación de la Ley de Protección a los Consumidores. Por otra parte, 8 juzgados de Policía Local no fueron considerados por imposibilidad de acceso a la información. A continuación se indican los tribunales seleccionados. ${ }^{6}$

En la muestra ejecutada en los 43 juzgados de Policía Local se constató el total de causas ingresadas durante el período de análisis, confundidas todas las materias, indicando el porcentaje para cada año estudiado. Del total de causas ingresadas por año se determinó el porcentaje relativo a procesos en que se invoca la Ley de Protección al Consumidor, ya sea sobre cláusulas abusivas u otra materia. En fin, se identificaron

${ }^{4}$ El diseño del modelo de muestra, procesamiento de los datos y construcción de tablas estuvo a cargo de la profesora socióloga Alejandra Ramm, del Instituto de Investigación en Ciencias Sociales de la Universidad Diego Portales.

${ }^{5}$ El estudio en terreno fue ejecutado entre el 10 de junio y el 23 de noviembre del año 2005. Fue realizado por tres alumnos egresados de derecho de la Universidad Diego Portales, doña Claudia Bahamondes, doña Bárbara Molina y don Juan Barahona, quienes visitaron los juzgados seleccionados para realizar las gestiones necesarias para obtener la información requerida. A todos ellos mis sinceros agradecimientos.

${ }^{6}$ Los tribunales excluidos fueron: $1^{\circ}$ y $2^{\circ}$ de Providencia, Lo Espejo, $1^{\circ}, 2^{\circ}$ y $5^{\circ}$ de Santiago, $1^{\circ}$ y $2^{\circ}$ de San Bernardo (todos estos por imposibilidad de acceso a la información), Antuco, Buin, Calera de Tango, Colina, El Monte, Isla de Maipo, Lampa, María Pinto, Melipilla, Paine, Peñaflor, Pirque, San José de Maipo, Curacaví, Padre Hurtado, Talagante y Tiltil (por ubicación y presunción de escasa cantidad causas de consumo). 
Tabla $\mathrm{N}^{\mathrm{o}} 1$

TRIBUNALES SELECCIONADOS

\begin{tabular}{|l|l|l|l|l|l|}
\hline 1 & $1^{\circ}$ La Florida & 16 & La Granja & 31 & La Reina \\
\hline 2 & $2^{\circ}$ La Florida & 17 & Recoleta & 32 & Peñalolén \\
\hline 3 & $3^{\circ}$ La Florida & 18 & $1^{\circ}$ Pudahuel & 33 & Lo Barnechea \\
\hline 4 & San Miguel & 19 & $2^{\circ}$ Pudahuel & 34 & $3^{\circ}$ Providencia \\
\hline 5 & La Cisterna & 20 & Lo Prado & 35 & $3^{\circ}$ Santiago \\
\hline 6 & $1^{\circ}$ Estación Central & 21 & La Pintana & 36 & $4^{\circ}$ Santiago \\
\hline 7 & $2^{\circ}$ Estación Central & 22 & Independencia & 37 & Macul \\
\hline 8 & $1^{\circ}$ Ñuñoa & 23 & El Bosque & 38 & $1^{\circ}$ Puente Alto \\
\hline 9 & $2^{\circ}$ Ñuñoa & 24 & Conchalí & 39 & $2^{\circ}$ Puente Alto \\
\hline 10 & Quinta Normal & 25 & Renca & 40 & Vitacura \\
\hline 11 & Quilicura & 26 & Cerro Navia & 41 & $1^{\circ}$ Las Condes \\
\hline 12 & Huechuraba & 27 & Cerrillos & 42 & $2^{\circ}$ Las Condes \\
\hline 13 & Pedro Aguirre Cerda & 28 & $1^{\circ}$ Maipú & 43 & $3^{\circ}$ Las Condes \\
\hline 14 & San Ramón & 29 & $2^{\circ}$ Maipú & & \\
\hline 15 & San Joaquín & 30 & $3^{\circ}$ Maipú & & \\
\hline & & \multicolumn{2}{|c}{} \\
\hline
\end{tabular}

los expedientes en que se litigaba sobre el control de cláusulas abusivas invocándose el artículo 16 de la ley. ${ }^{7}$

Un primer antecedente relevante el estudio es que durante los años 2002, 2003 y 2004, que comprenden un total de 1.609.762 causas, la distribución en el período presenta una mínima variación. En efecto, es fácil constatar que la distribución es bastante homogénea. Así, del total de causas, un 32,32\% corresponden al año 2002, un 35,01\% al 2003 y un $32,68 \%$ al 2004 . La mayor concentración se verifica en las comunas de Santiago (20,5\%), Estación Central (8,42\%), Las Condes $(8,11 \%)$, Recoleta $(5,73 \%)$ y La Florida $(5,01 \%)$, cuya suma arroja un $47,78 \%$ del total de causas ingresadas en el período.

\footnotetext{
${ }^{7}$ Sin embargo, esta última información no fue obtenida en los siguientes tribunales: $1^{\circ}, 2^{\circ}$ y $3^{\circ}$ de Las Condes, Vitacura y $3^{\circ}$ de Santiago. Hubo severos problemas de acceso a los expedientes -archivados fuera del recinto del tribunal o por falta de personal para practicar el desarchivo- o por negativa injustificada como ocurrió en el $3^{\circ}$ de Las Condes y $3^{\circ}$ de Santiago. Esta situación causa una distorsión en el análisis, pues se trata de juzgados que cabe presumir presentan una alta tasa de reclamos por concepto de materias de consumo. En ciertos casos, para intentar solucionar estos obstáculos se recurrió al libro de sentencias, en cuyo registro se indica -a veces- el artículo o artículos invocados y, por otra parte, se realizó una muestra aleatoria para acceder a un número más reducido de expedientes cuando se negó el desarchivo total.
} 
Tabla $\mathrm{N}^{\circ} 2$

TOTAL CAUSAS INGRESADAS

\begin{tabular}{|c|c|c|c|c|c|}
\hline $\begin{array}{l}\text { Tribunales } \\
\text { por comunas }\end{array}$ & $\begin{array}{c}\text { Total Período } \\
\left(\mathrm{N}^{\circ}\right)\end{array}$ & $\begin{array}{c}\text { Total Período } \\
(\%)\end{array}$ & $2002(\%)$ & $2003(\%)$ & $2004(\%)$ \\
\hline Santiago & 329.995 & 20,50 & 34,79 & 35,39 & 29,82 \\
\hline Estación Central & 135.601 & 8,42 & 28,01 & 41,50 & 30,49 \\
\hline Las Condes & 130.527 & 8,11 & 45,03 & 22,89 & 32,08 \\
\hline Recoleta & 92.301 & 5,73 & 27,45 & 35,57 & 36,98 \\
\hline La Florida & 80.672 & 5,01 & 29,71 & 32,24 & 38,05 \\
\hline Maipú & 70.387 & 4,37 & 31,11 & 33,34 & 35,56 \\
\hline Puente Alto & 55.792 & 3,47 & 33,24 & 35,36 & 31,40 \\
\hline Independencia & 52.327 & 3,25 & 36,69 & 32,91 & 30,40 \\
\hline Pudahuel & 50.458 & 3,13 & 35,64 & 41,39 & 22,97 \\
\hline Providencia & 49.095 & 3,05 & 0,57 & 50,11 & 49,32 \\
\hline Macul & 48.878 & 3,04 & 48,02 & 26,37 & 25,61 \\
\hline Ñuñoa & 48.124 & 2,99 & 38,16 & 35,51 & 26,33 \\
\hline Quilicura & 41.365 & 2,57 & 30,43 & 34,03 & 35,53 \\
\hline Pedro Aguirre Cerda & 35.367 & 2,20 & 31,79 & 31,84 & 36,38 \\
\hline San Miguel & 34.022 & 2,11 & 30,04 & 42,03 & 27,92 \\
\hline Vitacura & 31.637 & 1,97 & 35,06 & 30,26 & 34,68 \\
\hline La Pintana & 30.643 & 1,90 & 26,84 & 37,65 & 35,51 \\
\hline La Granja & 28.508 & 1,77 & 36,23 & 32,08 & 31,69 \\
\hline La Cisterna & 27.970 & 1,74 & 30,62 & 38,08 & 31,29 \\
\hline Cerrillos & 27.476 & 1,71 & 36,48 & 29,14 & 34,38 \\
\hline El Bosque & 25.041 & 1,56 & 24,30 & 34,24 & 41,45 \\
\hline Lo Prado & 24.010 & 1,49 & 25,58 & 38,81 & 35,61 \\
\hline San Joaquín & 23.853 & 1,48 & 32,95 & 33,32 & 33,73 \\
\hline Conchalí & 22.478 & 1,40 & 27,67 & 40,25 & 32,08 \\
\hline Renca & 20.427 & 1,27 & 31,43 & 35,84 & 32,73 \\
\hline Quinta Normal & 19.928 & 1,24 & 27,38 & 41,89 & 30,74 \\
\hline San Ramón & 18.999 & 1,18 & 28,44 & 36,07 & 35,50 \\
\hline Lo Barnechea & 15.233 & 0,95 & 31,24 & 32,76 & 36,00 \\
\hline Cerro Navia & 15.177 & 0,94 & 34,62 & 32,56 & 32,82 \\
\hline Huechuraba & 12.501 & 0,78 & 29,65 & 30,93 & 39,41 \\
\hline La Reina & 10.970 & 0,68 & 0,05 & 55,88 & 44,07 \\
\hline Peñalolén & $\mathrm{S} / \mathrm{I}$ & $\mathrm{S} / \mathrm{I}$ & $\mathrm{S} / \mathrm{I}$ & $\mathrm{S} / \mathrm{I}$ & $\mathrm{S} / \mathrm{I}$ \\
\hline TOTAL & 1.609 .762 & 100,00 & 32,32 & 35,01 & 32,68 \\
\hline
\end{tabular}

Para comprender la Tabla precedente debe considerarse que en la primera columna está la cifra total de causas ingresadas durante el período de análisis (2002, 2003 y 2004); luego la segunda columna muestra el porcentaje correspondiente a cada tribunal en relación al total de causas y, en seguida, en las tres columnas posteriores el porcentaje refiere a cada año en particular.

Otro dato relevante para la comprensión de la Tabla $\mathrm{N}^{\circ} 2$ es que muestra ingresos totales de causas, sin distinguir aquellas relativas a la protección del consumidor. Es decir, refleja el total de causas ingresadas en los tribunales considerando todas las materias confundidas. El dato relevante al relacionar dicho total con aquellas causas en que se invoca la Ley de Protección al Consumidor es la escasa o nula relevancia en porcentaje. 
En efecto, del total de causas ingresadas en el período estudiado - 1.609.762- un 0,25\% corresponde a procesos en que se esgrime la Ley de Protección al Consumidor, siendo un total de 3.971 causas. Eso sí debe considerarse que los juzgados de policía local tienen una amplia competencia en las materias más diversas y, por otra parte, como se dijo, es posible presumir que la falta de datos de algunos tribunales podría alterar el análisis, mas no la clara tendencia señalada.

En la Tabla $\mathrm{N}^{\circ} 3$ se indica el total de causas relativas a la protección del consumidor por tribunal, luego el porcentaje que ese número representa respecto al total de causas del consumidor todos los tribunales comprendidos y, por último, el porcentaje que dichas causas del consumidor representan en relación al total de causas ingresadas comprendidas todas las materias. Esto permite constatar que existe una mayor relevancia de causas de protección al consumidor en los juzgados de Santiago (25,02\%), Las Condes (18,18\%), Maipú (8,5\%) y La Florida (6,01\%). En conjunto representan un 57,71\% de las causas en materia de protección al consumidor. Sin considerar, como se dijo, tres tribunales de Santiago, que es posible presumir concentran un importante número de causas en la materia. ${ }^{8}$

Tabla $\mathrm{N}^{\circ} 3$

\section{CAUSAS LEY DEL CONSUMIDOR POR TRIBUNAL}

\begin{tabular}{|c|c|c|c|}
\hline $\begin{array}{l}\text { Tribunales } \\
\text { por comunas }\end{array}$ & Frecuencia & $\begin{array}{l}\text { (\%) del total de } \\
\text { causas consumidor }\end{array}$ & $\begin{array}{l}\text { (\%) Causas Ley del Consumidor } \\
\text { sobre Total Causas en general }\end{array}$ \\
\hline Santiago & 993 & 25,02 & 0,30 \\
\hline Las Condes & 723 & 18,18 & 0,55 \\
\hline Maipú & 336 & 8,50 & 0,48 \\
\hline La Florida & 239 & 6,01 & 0,30 \\
\hline Ñuñoa & 140 & 3,39 & 0,29 \\
\hline Estación Central & 135 & 3,39 & 0,10 \\
\hline Vitacura & 111 & 2,79 & 0,35 \\
\hline La Reina & 105 & 2,64 & 0,96 \\
\hline Cerrillos & 99 & 2,49 & 0,36 \\
\hline Providencia & 98 & 2,46 & 0,20 \\
\hline Renca & 93 & 2,34 & 0,46 \\
\hline Huechuraba & 88 & 2,21 & 0,70 \\
\hline El Bosque & 85 & 2,19 & 0,34 \\
\hline Recoleta & 79 & 1,99 & 0,09 \\
\hline Puente Alto & 75 & 1,89 & 0,13 \\
\hline Quinta Normal & 74 & 1,86 & 0,37 \\
\hline Pudahuel & 72 & 1,81 & 0,14 \\
\hline Macul & 63 & 1,58 & 0,13 \\
\hline La Cisterna & 57 & 1,43 & 0,20 \\
\hline Peñalolén & 51 & 1,28 & $\mathrm{~S} / \mathrm{I}$ \\
\hline Lo Barnechea & 48 & 1,21 & 0,32 \\
\hline Independencia & 45 & 1,13 & 0,09 \\
\hline San Miguel & 29 & 0,73 & 0,09 \\
\hline Conchalí & 28 & 0,70 & 0,12 \\
\hline Pedro Aguirre Cerda & 24 & 0,60 & 0,07 \\
\hline Lo Prado & 22 & 0,68 & 0,09 \\
\hline San Joaquín & 19 & 0,48 & 0,08 \\
\hline Quilicura & 14 & 0,35 & 0,03 \\
\hline San Ramón & 10 & 0,25 & 0,05 \\
\hline La Pintana & 9 & 0,23 & 0,03 \\
\hline Cerro Navia & 5 & 0,13 & 0,03 \\
\hline La Granja & 2 & 0,05 & 0,01 \\
\hline TOTAL & 3.971 & 100,00 & 0,25 \\
\hline
\end{tabular}

${ }^{8}$ Los tribunales de Estación Central y de Recoleta, si bien representan algo más del $5 \%$ de las causas totales, en relación a la Ley de Protección al Consumidor sólo suman un 3,39\% y un 1,99\%, respectivamente. 
La siguiente Tabla indica las causas totales en materia de consumidores, señalando los porcentajes por año.

Tabla $\mathrm{N}^{\circ} 4$

CAUSAS LEY DEL CONSUMIDOR SEGÚN AÑO

\begin{tabular}{|c|c|c|c|c|}
\hline Tribunales por comunas & Frecuencia & $2002(\%)$ & $2003(\%)$ & $2004(\%)$ \\
\hline Santiago & 993 & 22,16 & 36,56 & 41,29 \\
\hline Las Condes & 723 & 22,82 & 35,55 & 41,63 \\
\hline Maipú & 336 & 30,95 & 29,17 & 39,88 \\
\hline La Florida & 239 & 27,62 & 25,52 & 46,86 \\
\hline Ñuñoa & 140 & 29,29 & 38,57 & 32,14 \\
\hline Estación Central & 135 & 22,96 & 50,37 & 26,67 \\
\hline Vitacura & 111 & 35,14 & 15,32 & 49,55 \\
\hline La Reina & 105 & 25,71 & 37,14 & 37,14 \\
\hline Cerrillos & 99 & 19,19 & 31,31 & 49,49 \\
\hline Providencia & 98 & 0,00 & 30,61 & 69,39 \\
\hline Renca & 93 & 26,88 & 50,54 & 22,58 \\
\hline Huechuraba & 88 & 27,27 & 43,18 & 29,55 \\
\hline El Bosque & 85 & 89,41 & 4,71 & 5,88 \\
\hline Recoleta & 79 & 27,85 & 37,97 & 34,18 \\
\hline Puente Alto & 75 & 14,67 & 29,33 & 56,00 \\
\hline Quinta Normal & 74 & 12,16 & 47,30 & 40,54 \\
\hline Pudahuel & 72 & 43,06 & 38,89 & 18,06 \\
\hline Macul & 63 & 23,81 & 33,33 & 42,86 \\
\hline La Cisterna & 57 & 56,14 & 21,05 & 22,81 \\
\hline Peñalolén & 51 & 11,76 & 17,65 & 70,59 \\
\hline Lo Barnechea & 48 & 33,33 & 37,50 & 29,17 \\
\hline Independencia & 45 & 42,22 & 37,78 & 20,00 \\
\hline San Miguel & 29 & 37,93 & 44,83 & 17,24 \\
\hline Conchalí & 28 & 10,71 & 50,00 & 39,29 \\
\hline Pedro Aguirre Cerda & 24 & 37,50 & 25,00 & 37,50 \\
\hline Lo Prado & 22 & 31,82 & 45,45 & 22,73 \\
\hline San Joaquín & 19 & 57,89 & 36,84 & 5,26 \\
\hline Quilicura & 14 & 42,86 & 7,14 & 50,00 \\
\hline San Ramón & 10 & 60,00 & 20,00 & 20,00 \\
\hline La Pintana & 9 & 22,22 & 44,44 & 33,33 \\
\hline Cerro Navia & 5 & 0,00 & 40,00 & 60,00 \\
\hline La Granja & 2 & 0,00 & 0,00 & 100,00 \\
\hline TOTAL & 3.971 & 26,52 & 34,20 & 39,28 \\
\hline
\end{tabular}

Del análisis de la Tabla precedente puede observarse una tendencia al aumento en el período estudiado. Las causas correspondientes al año 2002 representan un 26,52\%, aquellas del 2003 un 34,2\% y las del año 2004 un 39,28\% del total. 
Ahora bien. Lo que interesa es lograr saber cuántas causas de entre aquellas sobre consumidores dicen relación con denuncias por cláusulas abusivas en contratos por adhesión. Del total de causas relativas a consumidores sólo se pudo acceder a un 53,1\% para verificar los artículos invocados. ${ }^{9}$

La revisión de los expedientes evidencia que sólo un 62,7\% de las causas donde corresponde señalar algún artículo lo hace. Es decir, un 37,3\% de las causas que debieran indicar un artículo esto no sucede.

Tabla $\mathrm{N}^{\circ} 5$

¿SEÑALA ARTÍCULO?

\begin{tabular}{|l|c|c|}
\cline { 2 - 3 } \multicolumn{1}{c|}{} & Frecuencia & $(\%)$ \\
\hline Sí & 1.323 & 62,7 \\
\hline No & 787 & 37,3 \\
\hline TOTAL & 2.110 & 100,0 \\
\hline
\end{tabular}

En cuanto a los artículos invocados en las causas, el artículo 23 es el más mencionado (en el 59,3\% de las causas), junto con el artículo 12 (54,7\% de las causas). Además estos dos artículos se suelen mencionar en conjunto, lo que sucede en un 46,3\%. Con menor frecuencia se invocan los artículos 3, 20, 50 y 54 (13,2\%; 12,6\%; 9,3\% y 5,1\%, respectivamente). Los demás artículos no alcanzan un $5 \%$ de menciones. Lo más habitual es que se invoquen dos artículos en cada causa. En lo que interesa a nuestro estudio, el artículo 16 es señalado sólo en un 2,1\% de las causas, lo que representa 28 expedientes.

En conclusión, el porcentaje y número de causas en que aparece mencionado el artículo 16 de la Ley de Protección a los Consumidores es ínfimo. Esto nos indica que la protección al consumidor en materia de contratos por adhesión tiene una aplicación extremadamente reducida en los juzgados de Policía Local, siendo el número de causas en que se analiza este problema irrelevante. Es cierto que este porcentaje podría variar al incluir los tribunales relevantes en que no se pudo obtener información. Sin embargo, es dable presumir que dicha variación no sería significativa al punto de invertir la tendencia mostrada.

Todavía debe señalarse que, a nivel general, en materia de protección al consumidor, las causas de término evidencian la escasa resolución favorable al demandante, con independencia del asunto de que se trate. Si bien el mayor porcentaje está dado por

Tabla No 6

CAUSAS ANALIZADAS ARTÍCULO INVOCADO

\begin{tabular}{|l|c|c|}
\cline { 2 - 3 } \multicolumn{1}{c|}{} & Frecuencia & $(\%)$ \\
\hline Sí & 2.110 & 53,1 \\
\hline No & 1.831 & 46,1 \\
\hline Total & 3.941 & 99,2 \\
\hline Casos perdidos & 30 & 0,8 \\
\hline TOTAL & 3.971 & 100 \\
\hline
\end{tabular}


la opacidad de la información $(35,9 \%)$, siguen en la forma de término más frecuente el "desistimiento y archivo" (20,4\%) y el "rechazo" (19,8\%). Estas son las principales formas en que terminan los litigios en materia de consumidores en el período estudiado. Con un menor porcentaje están "pendiente" $(8,6 \%)$, "acuerdo" $(8,0 \%)$ y "se acoge" $(7,3 \%)$. En conclusión, la forma menos frecuente de término de litigios en materia de consumidores es aquella en que se acoge la demanda del consumidor. ${ }^{10}$

Al cruzar las formas de término según año, se evidencia que las causas sin información respecto de su término y las pendientes son las que más se incrementan. Mientras que decrecen el "acuerdo", el "rechazo" y "se acoge". ${ }^{11}$

Tabla $N^{\circ} 8$

FORMAS DE TÉRMINO SEGÚN AÑO

\begin{tabular}{|l|c|c|c|c|}
\cline { 2 - 5 } \multicolumn{1}{c|}{} & 2002 & 2003 & 2004 & $\begin{array}{c}\text { Diferencia } \\
\text { ('04-'02) }\end{array}$ \\
\hline Sin información & 28,5 & 36,9 & 40,3 & 11,8 \\
\hline Desistimiento y archivo & 20,7 & 20,5 & 20,1 & $-0,6$ \\
\hline Se rechaza & 22,2 & 20,7 & 17,2 & $-5,0$ \\
\hline Pendiente & 5,4 & 8,4 & 11,0 & 5,6 \\
\hline Acuerdo & 13,7 & 5,4 & 6,2 & $-7,5$ \\
\hline Se acoge & 9,4 & 8,2 & 5,1 & $-4,3$ \\
\hline TOTAL & 100 & 100 & 100 & \\
\hline
\end{tabular}

Puede concluirse que la realidad de la protección de los consumidores en la materia estudiada es desoladora. No sólo son escasas las presentaciones ante los juzgados de Policía Local, en relación al universo de causas ingresadas, sino que la forma en que suelen resolverse es en contra del interés del consumidor. En lo que interesa al análisis, debe concluirse que el sistema de control de cláusulas abusivas previsto en la Ley 19.946, a pesar de presentar técnicas usuales en el derecho comparado continental, no se aplica

10

Tabla $\mathrm{N}^{\circ} 7$

FORMAS DE TÉRMINO

\begin{tabular}{|l|c|c|}
\cline { 2 - 3 } \multicolumn{1}{c|}{} & Frecuencia & $(\%)$ \\
\hline Sin información & 1.427 & 35,9 \\
\hline Desistimiento y archivo & 809 & 20,4 \\
\hline Se rechaza & 785 & 19,8 \\
\hline Pendiente & 341 & 8,6 \\
\hline Acuerdo & 318 & 8 \\
\hline Se acoge & 291 & 7,3 \\
\hline TOTAL & 3.971 & 100,0 \\
\hline
\end{tabular}

${ }^{11}$ Año 2002: 1.084 causas; 2003: 1.349 y 2004: 1.538 . 
con frecuencia, siendo un instrumento ineficaz para excluir cláusulas abusivas del mercado contractual. ${ }^{12}$

Por otra parte, la investigación empírica delata serias falencias en las formas de trabajo de los juzgados de Policía Local. Existe una nula sistematización en los procedimientos de ingreso y archivo, no se accede a la información con facilidad, las formas de tramitar las causas son dispares y, lo que es más grave, los razonamientos jurídicos están lejos de constituir soluciones coherentes y uniformes.

A continuación realizaremos un análisis de las escasas causas en que se ha invocado el sistema de control represivo.

\section{ESTUdIO DOGMÁTICO DE LAS SENTENCIAS SOBRE CONTROL DE CLÁUSULAS ABUSIVAS}

No volveremos a describir el sistema de control previsto en la Ley 19.496. Baste mencionar que su artículo 16 constituye la regla fundamental para excluir cláusulas abusivas de los contratos por adhesión, al establecer una cláusula general de buena fe desde el año 2004 y la ya referida lista de cláusulas prohibidas desde el año 1997, a lo cual cabe agregar ciertos mecanismos de control formales. ${ }^{13}$

Según se dijo, la investigación arrojó 28 procesos en que se invoca el artículo 16 como regla aplicable para la solución del litigio. De estos 28 procesos sólo 23 se refieren en forma específica al control de cláusulas abusivas. Para realizar el análisis de la jurisprudencia, nos referiremos, por una parte, a problemas sustantivos tratados (A), en segundo término, a problemas de índole procesal (B).

\section{A. Problemas sustantivos del control de cláusulas abusivas}

1. El contrato por adhesión. La primera cuestión, poco controversial en los fallos analizados, es la noción de contrato por adhesión. Los tribunales entienden esta forma de contratar sin dificultad, exigiendo que sea un contrato celebrado entre un proveedor y un consumidor y que el primero haya impuesto el contenido del contrato al segundo.

En sentencia de 27 de abril de 2004, el Tercer Juzgado de Policía Local de Santiago sostuvo que “...de la sola revisión de los términos de las condiciones generales del contrato en cuestión... aparece de manifiesto que encontrándose éstas en un formulario pre impreso por el proveedor, constituyen un contrato de adhesión, ya que el suscriptor no puede cambiar los términos de sus cláusulas, sino que sólo debe ingresar sus datos en el formulario..., y señalar el tipo de plan telefónico que desea, pero sin poder discutir el fondo de los artículos contractuales, por lo que resulta aplicable el artículo 16 de la

${ }^{12}$ Véase Pizarro Wilson, C., "Las cláusulas abusivas. Una crítica al control represivo”, en Revista de Derecho de la Pontificia Universidad Católica de Valparaíso, t. XXVI, 2005, pp. 391 y ss.

${ }^{13}$ Véase la bibliografía citada en nota $\mathrm{N}^{\circ} 1$. 
Ley 19.496". ${ }^{14}$ En un sentido análogo, otra sentencia señala que "entre la empresa y el cliente existe un contrato, llámese Condiciones Generales de Suscripción o como se llame, contrato que, también de toda evidencia, es de los llamados "de adhesión"; Que si bien es de la esencia de dichos contratos que el consumidor debe simplemente aceptar las cláusulas propuestas unilateralmente por el proveedor, sin que aquél pueda alterar su contenido..., es lo cierto que el artículo 16 de la misma ley, buscando a no dudarlo algún grado de equidad jurídica posterior, ya en el desarrollo del contrato...". ${ }^{15}$

Con reflexiones de índole más doctrinal, la Corte de Apelaciones de Santiago sostuvo en relación al contrato por adhesión que "Si bien este último instituto -el contrato de adhesión- ya tiene larga data de existencia, adquirió nuevos bríos con el derecho del consumidor, el cual se construye sobre la base que los consumidores acceden a la oferta de un bien conociendo sobre la base de una propuesta estándar del oferente, en la cual las opciones de modificación de las condiciones ofrecidas son limitadas y las más de las veces se reducen a la opción de adquirir o rechazar un producto". ${ }^{16}$

Las referidas sentencias confirman una noción amplia del contrato por adhesión sin detenerse sobre peculiaridades sobre otras formas contractuales como el contrato formulario, el contrato tipo o las propias condiciones generales o términos generales. En este sentido los fallos aplican la normativa de protección a cualquier contrato en que concurra un proveedor y un consumidor, estando este último imposibilitado de negociar el contenido contractual. De esta manera se despeja una preocupación doctrinal sobre la posible exclusión de protección para ciertas formas contractuales en que el proveedor no participaba en la redacción, bastando en la práctica que simplemente las proponga para la aceptación o rechazo por el consumidor.

En otro ámbito, la exigencia de celebración del contrato específico queda clara de una sentencia del Juzgado de Policía Local de Las Condes, según la cual "que si bien es cierto, el estudio realizado por el Servicio Nacional del Consumidor es en cumplimiento del mandato legal otorgado por el artículo 8 de la Ley 19.946, también es cierto que dicho estudio se basó en un formulario de contrato de servicio de suministro de Servicio Público Móvil de ENTEL PCS... y no con respecto a un contrato de adhesión suscrito por la denunciada y un consumidor”. Y se agrega en relación a la sanción por aplicación

${ }^{14}$ Santiago, 27 de abril de 2004, Causa Rol 12.922-AM/03.

${ }^{15}$ Las Condes, 11 de abril de 2003, Causa Rol 173.969-3. La sentencia del 3er Tribunal de Las Condes señala en otro fallo refiriéndose a un contrato de "tiempo compartido" que "respecto al contrato celebrado entre las partes, es preciso señalar que nos encontramos frente a un contrato de adhesión, por cuanto se ajusta a cabalidad a la definición que del contrato de adhesión da el artículo $1 \mathrm{~N}^{\circ} 6$ de la Ley 19.496, esto es aquel contrato cuyas cláusulas han sido propuestas unilateralmente por el proveedor sin que el consumidor, para celebrarlo, pueda alterar su contenido". Y agrega "que, los denominados contratos de adhesión por el hecho de contener cláusulas que no han sido libremente negociadas por las partes, sino que virtualmente son impuestas al consumidor por el predisponente (la parte que las redacta), y a fin de evitar abusos motivó la dictación por parte del legislador de normas de equidad en las estipulaciones y cumplimiento de dichos contratos...”.

${ }^{16}$ Corte de Apelaciones de Santiago, 5 de agosto de 2005, Rol No 7468-2003, redacción abogado integrante señor Guido Aguirre de la Rivera. 
de los artículos 16 y 17 de la ley, la nulidad absoluta "sólo puede ser denunciada por el adherente al contrato o consumidor, pues son sus intereses los protegidos por la ley". ${ }^{17}$ Estos razonamientos permiten desechar la denuncia interpuesta por el SERNAC. Sin perjuicio del razonamiento correcto del tribunal en cuanto a la necesidad de acuerdo entre un proveedor y un consumidor para estar en presencia de un contrato por adhesión al cual puede aplicarse el estatuto protector, la consecuencia de esta exigencia es que la acción preventiva del SERNAC carece de eficacia. En amparo a esta situación puede ejercerse una acción de interés difuso, definidas por la propia ley, luego de las reformas introducida el 2004, como aquellas acciones que se promueven en defensa de un conjunto indeterminado de consumidores afectados en sus derechos. Este tipo de acciones, además, en la hipótesis que se esgrima el artículo 16, 16 A o 17, según dispone el artículo $50 \mathrm{~A}$ inciso $3^{\circ}$, son de conocimiento de los tribunales ordinarios de justicia. Según nos informó en entrevista practicada al abogado subdirector del SERNAC en esta materia sólo se ha presentado una acción colectiva impugnando contrato de tiempo compartido. Sin embargo, el énfasis de la acción está en el derecho a retracto. ${ }^{18}$

2. Qué cláusulas se han estimado abusivas. De la revisión de las sentencias puede concluirse una presencia significativa de problemas con contratos de servicios telefónicos celulares. En este ámbito la cláusula impugnada por excelencia es aquella que permite al proveedor modificar en forma unilateral las tarifas o planes tarifarios. En la ya individualizada sentencia del tribunal de Las Condes de 10 de mayo de 2004, el SERNAC inició un procedimiento en virtud del artículo 8 de la Ley 19.496, luego de efectuar un estudio de formulario de contrato de suministro de Servicio Público Móvil ENTEL PCS, por el cual se constató la existencia de cláusulas abusivas al permitir modificar unilateralmente las tarifas o planes tarifarios. Sin embargo, la denuncia fue desestimada por no estar en presencia de un contrato. ${ }^{19}$

Es curioso que el mismo tribunal, el $3^{\circ}$ de Las Condes, el 14 de julio de 2004, ante denuncia del SERNAC en representación de una consumidora por modificación unilateral del precio del servicio de telefonía contratado, declaró su incompetencia. Para justificar esta resolución sostuvo que "el artículo $6^{\circ}$ de la Ley 18.168 General de Telecomunicaciones establece que le corresponderá al Ministerio de Transportes y Telecomunicaciones, a través de la Subsecretaría de Telecomunicaciones, la aplicación y control de la presente ley y sus reglamentos y le competerá además, exclusivamente, la interpretación técnica de las disposiciones legales y reglamentarias que rigen las telecomunicaciones, sin perjuicio de las facultades propias de los Tribunales”. Cita, además, el artículo $4^{\circ}$ del Reglamento sobre Tramitación y Resolución de Reclamos de Servicios

${ }^{17}$ Las Condes, 10 de mayo de 2004, Causa Rol 15.706-2003.

${ }^{18}$ Entrevista practicada al abogado de la División Jurídica y Subdirector del Sernac, Sergio Corvalán, enero 2007.

${ }^{19}$ Las Condes, 10 de mayo de 2004, 3er Juzgado de Policía Local de Las Condes, Rol 15.706. La sanción de excluir la cláusula abusiva del contrato luego de la reforma del 2004 no es absoluta, pues el juez debe declarar la nulidad de la totalidad del contrato si considera que por la naturaleza del contrato o atendida la intención original de los contratantes ello no fuere posible. Véase artículo $16 \mathrm{~A}$. 
de Telecomunicaciones aprobado por DS N 566 y termina expresando que el contrato consagra una cláusula en que se dispone la solución de las controversias por árbitro arbitrador. ${ }^{20}$ Sin embargo, se trata de una posición rechazada por la Corte de Apelaciones de Santiago. En dos fallos de 8 de octubre de 2004 y 12 de octubre de 2005.

Se reconoce competencia a los juzgados de policía local para conocer al amparo de la Ley de Protección al Consumidor los reclamos por incumplimiento de contratos de telefonía móvil. ${ }^{21}$

Por su parte, el juzgado de Policía Local de Recoleta en un contrato de asistencia médica sostuvo que "La Ley 19.496, morigerando el rigor de la sacrosanta ley del contrato (art. 1545 del Código Civil), dispone normas de equidad en las estipulaciones y en el cumplimiento de los contratos de adhesión. Así el artículo 16 dispone...”. Y continúa señalando que la cláusula que faculta al proveedor poner término al contrato en forma unilateral vulnera el artículo 16 letra a) y no produce efecto alguno. ${ }^{22}$

En otra sentencia, por modificación unilateral del contrato contra Chilesat S.A., se señaló que "el proveedor del servicio no respetó los términos, condiciones y modalidad conforme a la cual convino con el consumidor la prestación del servicio, celebrado por las partes... La regla general establece que todo contrato legalmente celebrado es una ley para los contratantes y no puede ser invalidado sino por su consentimiento mutuo o por causas legales...”. Es decir, a partir del principio de la fuerza obligatoria del contrato previsto en el artículo 1545 del Código Civil, el tribunal estima improcedente la modificación unilateral dando por infringido el artículo 16 letra b). ${ }^{23}$

El $3^{\text {er }}$ juzgado de Policía Local de Las Condes tuvo la ocasión de pronunciarse acerca de la validez de cláusulas consideradas limitaciones absolutas de responsabilidad del proveedor, privando al consumidor de su derecho al resarcimiento. La causa es interesante al relacionar la limitación absoluta con la cláusula penal impuesta a favor del

${ }^{20}$ Las Condes, 14 de julio de 2004, Tercer Juzgado de Policía Local de Las Condes, Rol 17.970.

${ }^{21}$ Véase Corte de Apelaciones de Santiago, No de ingreso 1534-2003 y 7888-2004. En este último fallo, en lo principal se sostuvo: "Que, si bien la Subsecretaría de Comunicaciones -SUBTEL-, del Ministerio de Transporte y Telecomunicaciones es el organismo competente para el conocimiento de las contravenciones a la Ley General de Telecomunicaciones, dicha Subsecretaría fiscaliza las entidades dedicadas a las comunicaciones y sanciona las infracciones de tipo técnico referidas a las transmisiones y al otorgamiento y demás cuestiones provenientes de las concesiones otorgadas; $4^{\circ}$.- Que la SUBTEL, conforme a lo señalado en el artículo 28 bis de la Ley 18.168, resolverá los reclamos que se formulen por, entre o en contra de concesionarios, usuarios y particulares en general, que se refieran a cualquier cuestión derivada de dicha ley, de sus cuerpos reglamentarios y de los planes y normas técnicas, por lo que resulta evidente que es un ente administrativo que revisa cuestiones técnicas, pero no jurisdiccionales, en circunstancias que les corresponde a los tribunales de justicia, de acuerdo a lo que dispone el artículo 50 de la Ley 19.496, conocer de las infracciones que vulneran los derechos de los consumidores; $5^{\circ}$.- Que, por otra parte, el artículo $6^{\circ}$ de la Ley 18.168 luego de señalar que le corresponde al Ministerio de Transporte y Telecomunicaciones, a través de la Subsecretaría de Telecomunicaciones, la aplicación y control de dicha ley y de sus reglamentos, dispone expresamente: "Le competerá, además, exclusivamente la interpretación técnica de las disposiciones legales y reglamentarias que rigen las telecomunicaciones, sin perjuicio de las facultades propias de los tribunales de justicia ....”.

${ }^{22}$ Recoleta, 15 de julio de 2003, Juzgado de Policía Local de Recoleta, Rol 50.463.

${ }^{23}$ Huechuraba, 22 de octubre de 2003, Juzgado de Policía Local de Huechuraba, Rol 55.644. 
proveedor en el evento de operar el desistimiento por parte del consumidor. En la parte pertinente el tribunal estimó que "la citada cláusula -penal- en la práctica hace que el desistimiento del contrato no sea más que una simple ilusión”. Por lo demás, tratándose de un contrato de "tiempo compartido" el tribunal consideró al consumidor víctima de engaño, concluyendo que "de conformidad con la facultad otorgada por el artículo 16 de la Ley 19.496 y, atendido a que el contrato es en sí abusivo y fue obtenida la anuencia a él por parte de la demandante producto de un engaño acoge la solicitud y declara que el contrato debe anularse". ${ }^{24}$

En otro ámbito y con carácter excepcional, se presentó una querella infraccional y demanda civil por infracción a las letras d) y e) del artículo 16. Esto es, las cláusulas que inviertan la carga de la prueba en perjuicio del consumidor -letra d-y que "contengan limitaciones absolutas de responsabilidad frente al consumidor que pueden privar a éste de su derecho a resarcimiento frente a deficiencias que afecten la utilidad o finalidad esencial del producto o servicio" - letra e)-. En estos autos la querella decía relación con un contrato de "tiempo compartido". Al no haberse probado una supuesta resciliación del contrato aseverada por la querellante, el tribunal en virtud del principio de la fuerza obligatoria validó en su totalidad los efectos del contrato suscrito por las partes, así como el cobro del pagaré por el saldo de la deuda. ${ }^{25}$

Bajo el amparo del mismo principio de la fuerza obligatoria del contrato, el Juzgado de Policía Local de Las Condes rechaza la denuncia infraccional e indemnización de perjuicios por alza unilateral de tarifa de conexión a internet. Para desestimar la pretensión del consumidor el tribunal sostuvo que "de conformidad a lo dispuesto en el artículo 1545 del Código Civil, todo contrato legalmente celebrado es una ley para los contratantes, por lo que habiendo las partes estipulado que el contrato de conexión a internet es accesorio al del servicio de Televisión por cable y que las estipulaciones generales del mismo forman parte integrante de éste, han establecido, en consecuencia, como regla en sus obligaciones contractuales la aplicación subsidiaria de las cláusulas del contrato principal en lo no regulado por el contrato accesorio, entre las cuales se encuentra la cláusula de reajustabilidad...debiendo primar...la voluntad manifestada por las partes al momento de suscribir el contrato objetado". ${ }^{26}$

Sin embargo, en una causa similar por denuncia de modificación unilateral, se estima infringido el artículo 16 letras a) y b) al haberse modificado de manera unilateral el contrato de adhesión original al imponer un reajuste en su precio, siendo condenado el proveedor.

${ }^{24}$ Las Condes, 10 de diciembre de 2004, Juzgado de Policía Local de Las Condes, Rol 19.216.

${ }^{25}$ Santiago, 12 de marzo de 2004, Tercer Juzgado de Policía Local de Santiago, causa Rol 9669.

${ }^{26}$ Las Condes, 19 de agosto de 2003, $2^{\circ}$ Juzgado de Policía Local de Las Condes, Rol 85.608-5. En un sentido análogo a propósito de un alza unilateral del precio del servicio contratado, se rechaza en virtud de la fuerza obligatoria del contrato la denuncia y demanda civil por existir un acuerdo contractual existiendo el derecho a rechazar el aumento de precio poniendo término al contrato por parte del consumidor. Las Condes, 25 de septiembre de 2003, $2^{\circ}$ Juzgado de Policía Local, Rol 93.260. 
Puede observarse que la conclusión es diversa en las sentencias al considerarse en el segundo caso que no hubo respeto de las formas para proceder a la modificación unilateral, sin que exista un cuestionamiento absoluto de dicha facultad bajo condición de que se verifique en la oportunidad, periodicidad, forma y monto indicados en el contrato. ${ }^{27}$

El tribunal de Las Condes $\left(2^{\circ}\right)$, fiel al principio de la fuerza obligatoria del contrato, rechazó la denuncia infraccional por modificación unilateral del precio del servicio de cable -artículo 16 letra b)-, pero, tal como se anunció, la Corte de Apelaciones de Santiago dejó sin efecto la sentencia, en razón de que no se hace ninguna otra referencia al precio, ni tampoco existe claridad para el consumidor acerca de modificaciones del mismo, y agrega que "La referencia de la empresa ... a que el consumidor tiene la opción de discontinuar el servicio, si no está de acuerdo con el ajuste de los precios, no altera la infracción cometida en cuanto a la variación unilateral del precio y es más, así planteada la terminación puede considerarse una cláusula abusiva".28

Expuestas las sentencias más relevantes, se constata que el ámbito en que incide el control de cláusulas abusivas es muy reducido. Aún más, las temáticas en que se han pronunciado los juzgados de Policía Local impiden extraer conclusiones generales. Con todo, puede aseverarse que existe una total falta de uniformidad en la solución de los problemas atingentes a las cláusulas abusivas. Que el articulado del artículo 16 es poco utilizado, incluso con un predominio absoluto de la letra b) que impide la modificación unilateral del contrato por el proveedor. Por lo demás, en varias sentencias la fuerza obligatoria del contrato justifica rechazar las pretensiones de los consumidores, debiendo entenderse este principio atenuado por la ley de protección al consumidor y, con mayor razón, con la modificación que introduce la buena fe como cláusula general.

En consecuencia, a la escasa presencia del problema en los tribunales viene a sumarse un conjunto de sentencias dispersas sin mayor contenido dogmático.

\section{B. Aspectos procesales}

Existen severos problemas de asistencia jurídica a los consumidores para defender sus derechos. De esto dan cuenta ciertas sentencias. Así, por ejemplo, en la causa fallada por el Tercer Juzgado de Policía Local de Santiago en que se denunciaba una modificación unilateral del contrato de telefonía celular, por infracción al artículo 16 letra a), el tribunal estimó que la denunciada en forma unilateral modificó los términos del seguro contratado, incurriendo en infracción al artículo 12 de la Ley 19.496 en relación al artículo 1545 del Código Civil. Sin embargo, respecto al artículo 16, el tribunal "al no contar con un ejemplar del contrato en cuestión, carece de los elementos de convicción necesarios para establecer si el mismo era o no de adhesión, y si sus cláusulas se facultaba

\footnotetext{
${ }^{27}$ Las Condes, 11 de abril de 2003, 1er Juzgado de Policía Local de Las Condes.

${ }^{28}$ Sentencia citada, cit $N^{\circ} 16$. Cfr. Santiago, 27 de abril de 2004, Juzgado de Policía Local de Santiago,
} Rol 12922. 
(sic) o no a la querellada para modificarlo". ${ }^{29}$ Y en otro fallo se indica "que en lo que respecta al daño moral, no se rindió en el proceso prueba alguna tendiente a acreditar perjuicios de la índole señalada, razón por la cual este sentenciador desechará la demanda en ese sentido". ${ }^{30} \mathrm{Y}$ en otra denuncia efectuada por incumplimiento de obligación de información respecto al precio por exceder los minutos del plan telefónico móvil, el tribunal sostuvo que "a falta de otras pruebas que acrediten lo contrario, el sentenciador rechazará la denuncia infraccional...”.31

Estas sentencias muestran la falta de asesoría legal idónea de los consumidores frente a profesionales que asisten a las empresas proveedoras.

Por otra parte, si bien el SERNAC patrocina ciertas causas procediendo a denunciar ante los juzgados de policía local la vulneración de la Ley de Protección al Consumidor, tampoco se percibe un impacto favorable para el consumidor. Hasta ahora no se han presentado demandas colectivas en esta materia, no pareciendo ser un tema prioritario para el SERNAC la protección de los consumidores en materia de contratos por adhesión. Sin perjuicio de esta percepción, en el sitio web http://www.sernac.cl/tramites/index. php aparece formulario judicial para anular una cláusula abusiva en un contrato por adhesión. En el mismo sitio aparece citada sentencia en que se anula cláusula abusiva por permitir la modificación unilateral del contrato de telefonía móvil. Se hace necesario un papel más activo en esta materia tanto del SERNAC como de las asociaciones de consumidores, pudiendo, como se dijo, recurrir a acciones de interés difuso ante los juzgados civiles.

\section{CONCLUSIÓN}

De lo expuesto puede constatarse que el sistema de control de cláusulas abusivas vigente en la Ley de Protección del Consumidor es ineficiente para proteger a los consumidores. Existen diversos factores que pueden explicar esta anomalía. En primer lugar, el SERNAC no ha tenido una política clara y constante destinada a proteger a los consumidores en este ámbito. Esto podría lograrse con un trabajo más sistemático de carácter sectorial que permita constatar cuáles cláusulas abusivas están presentes por áreas específicas de la economía. Así, por ejemplo, en telefonía, televisión por cable, grandes tiendas, créditos de consumo, productos bancarios, etc. En mi opinión, el trabajo del SERNAC debiera avanzar a realizar un informe anual sobre cláusulas abusivas que permita constatar la vulneración de la Ley de Protección al Consumidor en esta materia. Este informe debiera publicitarse entre los actores relevantes, ya sea los proveedores y las organizaciones de consumidores, a fin de que los primeros excluyan las cláusulas en cuestión y las segundas, cuando sea necesario, inicien juicios colectivos para impedir la

\footnotetext{
${ }^{29}$ Santiago, 30 de julio de 2003, Tercer Juzgado de Policía Local de Santiago, causa Rol 13.388.

${ }^{30}$ Sentencia citada en nota (20).

${ }^{31}$ La Florida, 8 de octubre de 2002, Rol 14.099.
} 
presencia de las referidas cláusulas. Me parece que un sistema con estas características puede ser más eficiente que recurrir a los tribunales para ejercer un control represivo. Esta idea está respaldada por el estudio empírico expuesto, pues los juzgados de Policía Local no han mostrado eficacia para proteger a los consumidores, ya sea porque la diversidad de materias que están bajo su competencia impide una necesaria especialización y conocimiento, como la escasa uniformidad para tratar estos problemas. Una política pública eficaz debiera, entonces, promover un control preventivo y, sólo por excepción, judicializar el control de cláusulas abusivas. Además, el análisis realizado muestra que los juzgados de Policía Local en un porcentaje reducido favorecen al consumidor. Esto puede tener diversas explicaciones. La primera es que los consumidores carecen, en general, de una asesoría legal idónea, frente a abogados de proveedores que con frecuencia enfrentan este tipo de litigios, habiendo desarrollado una expertise en la materia. Es fácil constatar en los procesos estudiados una clara ausencia de prueba rendida por los consumidores, siendo, en general, a su carga rendirla. Esto sin considerar el abandono de los procesos. Por otra parte, los tribunales no acceden a indemnizar perjuicios y en las escasas sentencias favorables al consumidor, se limitan al ámbito infraccional multando al proveedor. Detrás de este problema está la escasa prueba para probar perjuicios, ya sean materiales o morales derivados de la presencia de cláusulas abusivas.

A partir del análisis crítico del sistema represivo en cuanto a su aplicación práctica, queda pendiente la elaboración de una propuesta de control preventivo que complemente la lucha contra las cláusulas abusivas.

\section{BIBLIOGRAFÍA}

Aimone Gibson, E., Derecho de protección al consumidor, Santiago, Conosur, 1998.

Corral Talciani, H. (editor), Derecho del consumo y protección al consumidor, Cuadernos de Extensión, Universidad de los Andes, Facultad de Derecho, Santiago, 1999.

De la Maza Gazmuri, I., "El control de las cláusulas abusivas y la letra g)", en Revista Chilena de Derecho Privado, No 3, 2004.

López Santa-María, J., "Cláusulas Contractuales Abusivas y Derecho del Consumidor", en Instituciones Modernas de Derecho Civil. Homenaje al Profesor Fernando Fueyo Laneri, Santiago, Conosur, 1996.

López Santa-María, J., "Condiciones Generales de la Contratación y Cláusulas Abusivas", en Cuadernos Jurídicos. Facultad de Derecho. Universidad Adolfo Ibáñez, 1996, No 4.

Pizarro Wilson, C., "La eficacia del control de las cláusulas abusivas en el derecho chileno", en Revista Estudios Socio-Jurídicos, Universidad del Rosario, Bogotá, Colombia, 2004.

Pizarro Wilson, C., La protección de los consumidores en materia contractual, Jurídica Conosur, Santiago, 1999.

Pizarro Wilson, C., "Las cláusulas abusivas. Una crítica al control represivo", en Revista de Derecho de la Pontificia Universidad Católica de Valparaíso, t. XXVI, 2005.

Tapia Rodríguez, M. y Valdivia Olivares, J. M., Contrato por adhesión: Ley 19.496, Santiago, Jurídica, 2002.

Veloso Valenzuela, P., "Cláusulas abusivas", en Instituciones modernas de derecho civil: homenaje al Profesor Fernando Fueyo Laneri, Santiago, Jurídica Conosur, 1996. 
